УДК 582.711.711:577.13

\title{
СЕЗОННАЯ ДИНАМИКА СОСТАВА ФЕНОЛЬНЫХ СОЕДИНЕНИЙ ЛИСTЬEB SPIRAEA MEDIA VAR. SERICEA (TURCZ.) REGEL
}

\author{
() Е.А. Карпова", Т.А. Полякова \\ Центральный сибирский ботанический сад СО РАН, ул. Золотодолинская, \\ 101, Новосибирск, 630090 (Россия), e-mail: karyevg@mail.ru
}

\begin{abstract}
Впервые изучена динамика состава фенольных соединений листьев растений S. media var. sericea в течение вегетационного периода методом ВЭЖХ. Основными компонентами комплекса фенольных соединений являются гликозиды кверцетина. Содержание флавонолгликозидов достигало максимума в фазе созревания плодов (3\%). Наиболее полный состав флавонолгликозидов отмечен в начале плодоношения. В экстракте в различные фазы вегетации в свободном виде обнаружены также галловая, протокатеховая, хлорогеновая, кофейная кислоты, кверцетин. В течение вегетации сохранялось постоянство состава агликонов при определенных различиях в составе флавонолгликозидов.

Ключевые слова: Spiraea, флавоноиды, кверцетин, сезонная динамика.
\end{abstract}

\section{Введение}

Сезонная динамика химического состава растений в течение вегетационного периода характеризует хронографическую изменчивость - одну из компонент внутривидовой изменчивости. Важность ее изучения состоит в определении диапазонов признаков и, таким образом, в возможности более точного и адекватного описания растения как представителя того или иного биологического вида. Особенно актуальны исследования сезонной изменчивости для так называемых спорных видов, которые большинством исследователей относятся к подвидам или разновидностям.

Spiraea media var. sericea (Turcz.) Regel является разновидностью Spiraea media, отличающейся от нее более выраженным опушением листовой пластинки. Сравнение по морфологическим признакам, не связанным с опушением листьев, и по составу фенольных соединений не показало достоверных отличий образцов, описанных как $S$. media var. sericea от образцов $S$. media $[1,2]$. Отсутствие отличий выборок вида и его разновидности может быть связано не только с характером географической изменчивости, но и с некорректной идентификацией образцов.

В такой ситуации аутентичные образцы S. media var. sericea, полученные из природной популяции растений в различные фазы вегетации, являются ценным источником для изучения внутривидовой изменчивости состава фенольных соединений этой разновидности S. media.

В составе флавоноидов листьев $S$. media и $S$. media var. sericea обнаружены гликозиды кверцетина (авикулярин, гиперозид, рутин, дипентозид, изокверцитрин), кемпферола (астрагалин) и изорамнетина (рамноглюкозид) [2, 3].

Целью нашего исследования является анализ динамики состава фенольных соединений в листьях

Карпова Евгения Алексеевна - старший научный сотрудник лаборатории фитохимии, кандидат биологических наук, тел.: 8 (383) 339-98-11, e-mail: karyevg@mail.ru

Полякова Татьяна Александровна - старший научный сотрудник лаборатории популяционной генетики Института общей генетики им. Н.И. Вавилова РАН, кандидат биологических наук, доцент, тел.: 8 (499) 135-50-67, e-mail:tat-polyakova@yandex.ru

\footnotetext{
* Автор, с которым следует вести переписку
} растений $S$. media var. sericea в течение вегетационного периода 2010 г.

\section{Экспериментальная часть}

Для исследования взяты листья растений S. media var. sericea, произрастающих в Ольгинском 
районе Приморского края (окрестности села Пермское), собранные в фазах цветения (8.06.2010), начала плодоношения (5.07.2010), массового созревания плодов (10.08.2010) и окончания вегетации (листопада) (22.09.2010). С каждого растения равномерно по всей кроне отбирали по 5-10 годичных побегов. Сильно отличающиеся по размеру или имеющие повреждения листья выбраковывались.

Состав и содержание фенольных соединений водно-спиртовых экстрактов листьев изучали до и после гидролиза методом высокоэффективной жидкостной хроматографии (ВЭЖХ). Точную навеску воздушносухого растительного материала (0,1 г) исчерпывающе экстрагировали 70\%-ным этанолом на водяной бане при температуре 60-70 드. Гидролиз проводили $2 \mathrm{~N}$ соляной кислотой на кипящей водяной бане в течение 2 ч.

Состав и содержание фенольных соединений определяли на аналитической ВЭЖХ-системе, состоящей из жидкостного хроматографа «Agilent 1200» с диодноматричным детектором и системы для сбора и обработки хроматографических данных ChemStation. Разделение проводили на колонке Zorbax SB-C18, paзмером 4,6×150 мм, с диаметром частиц 5 мкм при градиентном режиме метанола, подкисленного водным раствором ортофосфорной кислоты (0,1\%): для экстрактов - от 32 до 100\% метанола за 54 мин, для гидролизатов - от 50 до $100 \%$ метанола за 17 мин. Температура колонки $26^{\circ} \mathrm{C}$. Объем вводимой пробы 5 мкл.

Скорость подачи элюента 1 мл/мин. Перед использованием подвижную фазу фильтровали через мембранный фильтр с диаметром пор 0,45 мкм. Детектирование осуществляли при 255, 270, 290, 325, 340, 360 и 370 нм. Идентификацию известных соединений осуществляли сравнением со стандартными образцами. Расчет содержания неидентифицированных компонентов производили по стандартным площадям пиков галловой кислоты (для фенолкарбоновых кислот), гиперозида (для флавонолгликозидов) и кверцетина (для агликонов флавонолов).

\section{Обсуждение результатов}

В гидролизатах $S$. media var. sericea обнаружено 21 соединение, три из которых в соответствии с хроматографическими и спектральными характеристиками отнесены к агликонам флавонолов. Сопоставление времен удерживания $\left(\mathrm{t}_{\mathrm{r}}\right)$ пиков веществ и УФ-спектров на хроматограммах анализируемых образцов с временами удерживания и УФ-спектрами стандартных образцов позволило идентифицировать следующие компоненты: галловую, протокатеховую, $n$-оксибензойную, хлорогеновую, кофейную, $n$-кумаровую, o-кумаровую, коричную кислоты, кверцетин, кемпферол.

Доминирующим компонентом в течение всего периода вегетации является кверцетин, содержание которого достигает максимума в фазе созревания плодов (1\%). В относительно высоком количестве выявлены также протокатеховая кислота, содержание которой находится в пределах $(0,3-0,4 \%)$ и неидентифицированный флавоноид A1 ( $\left.\mathrm{t}_{\mathrm{r}} 2,9\right)$ (рис. 1,2$)$.

Большая часть обнаруженных соединений (19) выявлена во всех фазах вегетации, кроме коричной кислоты (найдена в последних двух фазах в незначительных количествах до 0,004\%) и неидентифицированного компонента $\left(\mathrm{t}_{\mathrm{r}} 8,6\right)$, напротив, обнаруженного только в две первые фазы в количестве около $0,02 \%$.

Содержание суммы фенолкарбоновых кислот достигало максимума в фазе начала плодоношения, суммы флавоноидов - в фазе созревания плодов (рис. 3).

Изменение содержания большей части соединений в течение вегетации составляло 20-40\%, более значительные колебания обнаружены в содержании п-оксибензойной, хлорогеновой, кофейной кислот и кверцетина (70\% и выше).

В экстрактах $S$. media var. sericea найдено 22 соединения, 15 из которых в соответствии с хроматографическими и спектральными характеристиками отнесены к флавоноидам. По времени удерживания и УФ-спектрам были идентифицированы галловая, протокатеховая, хлорогеновая, кофейная кислоты, кверцетин, гиперозид и рутин.

Галловая кислота в свободном виде обнаружена во всех фазах вегетации, протокатеховая - только в начале плодоношения, хлорогеновая - во всех фазах, кроме цветения, кофейная - в фазе созревания плодов и окончания вегетации. Кверцетин в свободном виде найден во всех фазах, кроме цветения. Максимум его содержания отмечен в фазе массового созревания плодов $(0,046 \%)$.

Содержание суммы свободных фенолкарбоновых кислот и агликонов флавоноидов в течение вегетации изменялось незначительно (рис. 4). 
Рис. 1. Основные компоненты

гидролизатов $S$. media var. sericea в фазах цветения и начала плодоношения (\% от абсолютно сухой массы). Условные обозначения: GA - галловая кислота, ChA - хлорогеновая кислота, РА - протокатеховая кислота, PhbA - n-оксибензойная кислота, КА - кофейная кислота, p-CA - $n$-кумаровая кислота, FA - феруловая кислота, А1 - неидентифицированный компонент, о-СА - o-кумаровая кислота, Q - кверцетин, К - кемпферол,

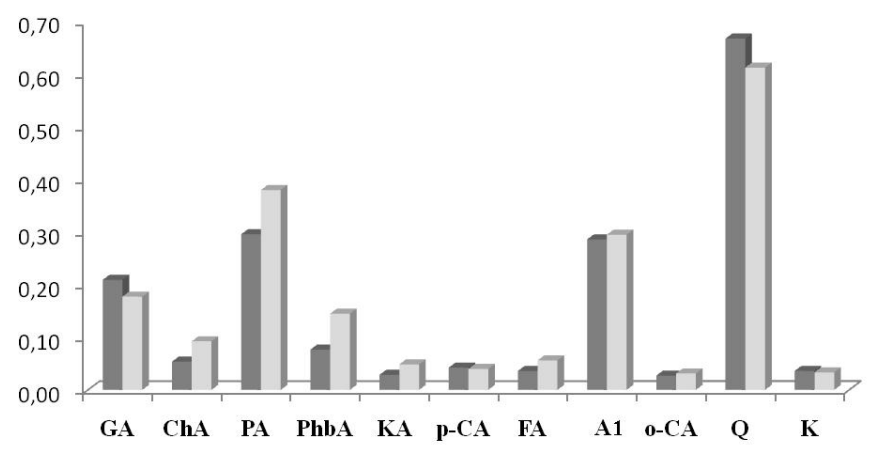
$\square$ - цветение, $\square$ - плодоношение

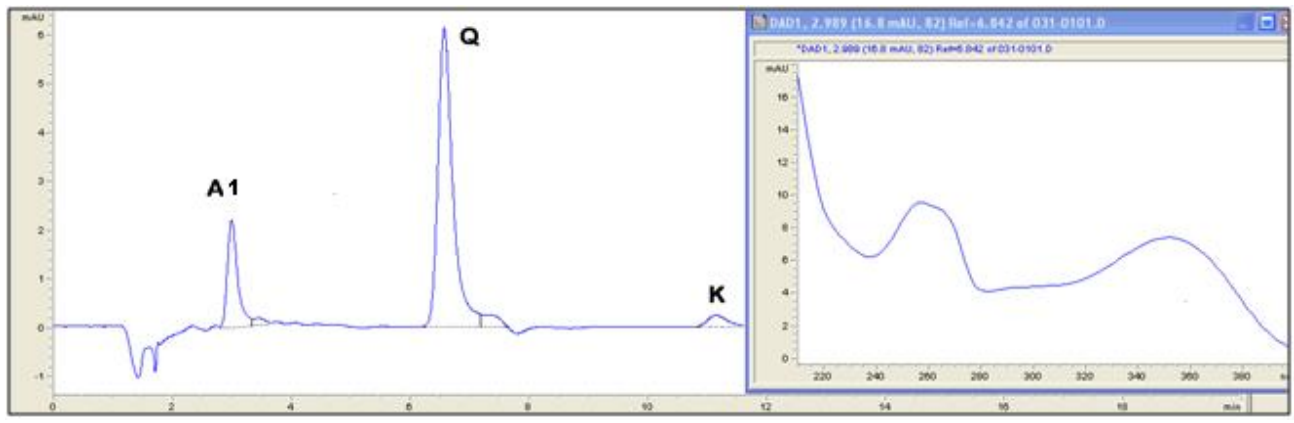

Рис. 2. Хроматограмма гидролизата S. media var. sericea в фазе цветения (детекция при 370 нм) и УФспектр флавоноида А1. Условные обозначения: А1 - неидентифицированный компонент $\mathrm{t}_{\mathrm{r}} 2,9$ мин, $\mathrm{Q}$ - кверцетин $\mathrm{t}_{\mathrm{r}} 6,5$ мин, $\mathrm{K}$ - кемпферол $\mathrm{t}_{\mathrm{r}} 10,9$ мин

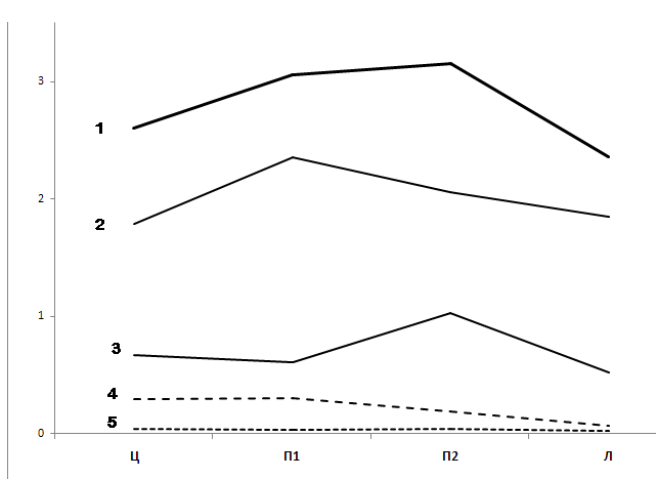

Рис. 3. Динамика фенолкарбоновых кислот и флавоноидов (\% от абсолютно сухой массы) в гидролизатах $S$. media var. Sericea. Условные обозначения: 1 - сумма фенольных соединений, 2 - сумма фенолкарбоновых кислот, 3 - кверцетин, 4 - агликон A1, 5 - кемпферол, Ц - цветение, П1 - начало плодоношения, П2 - созревание плодов, Л - листопад

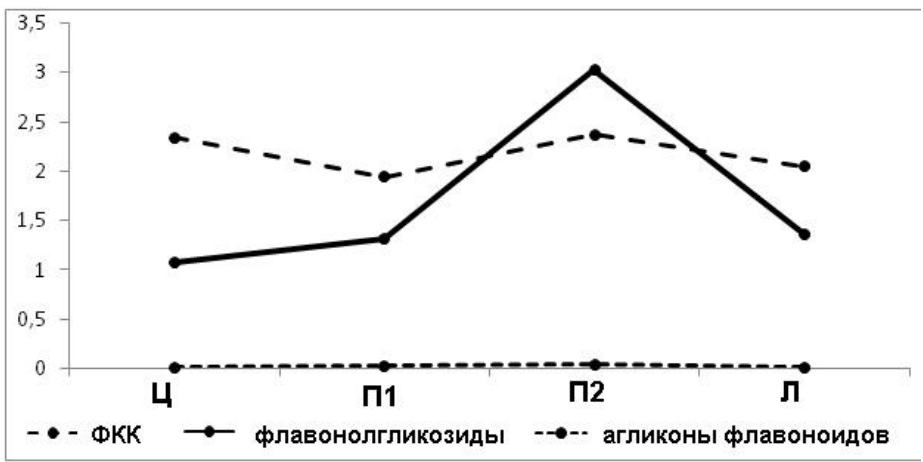

Рис. 4. Динамика свободных фенолкарбоновых кислот (ФКК) и флавоноидов (\% от абсолютно сухой массы) в экстрактах S. media var. Sericea. Условные обозначения: Ц - цветение, П1 - начало плодоношения, П2 - созревание плодов, Л - листопад

Содержание флавонолгликозидов в фазе цветения было минимальным (1\%), затем несколько возрастало к фазе начала плодоношения (1,3\%), далее к фазе созревания плодов увеличивалось более чем в 2 раза и достигало максимума (3\%). К окончанию вегетации содержание флавонолгликозидов понижалось до исходного уровня. 
Флавонолгликозиды были представлены главным образом гиперозидом, неидентифицированным компонентом $19\left(\mathrm{t}_{\mathrm{r}} 27,8\right)$ и рутином. Содержание этих компонентов также достигало максимума в фазе созревания плодов (рис. 5).

Максимум содержания некоторых флавонолгликозидов приходился на фазу цветения (компоненты 17 и 13), в которой они доминировали в сумме флавоноидов, а затем их содержание значительно уменьшалось.

Таким образом, состав флавонолгликозидов в течение сезона вегетации изменялся. Наиболее полный состав флавонолгликозидов (12) был отмечен в фазах начала плодоношения и окончания вегетации, минимальный состав (8) - в фазе цветения. Компоненты, отсутствующие в фазах плодоношения, за исключением флавонолгликозида GM-13, являются минорными компонентами, содержание которых не превышает $0,05 \%$. Во всех фазах вегетации обнаружены только пять флавонолгликозидов, в том числе гиперозид и флавонолгликозид GM-17.

Таким образом, состав агликонов флавоноидов S. media var. sericea и связанных фенокарбоновых кислот на протяжении всего сезона вегетации оставался неизменным. В экстракте полнота состава флавонолгликозидов достигалась только к фазе плодоношения, и большинство компонентов сохранялись на протяжении плодоношения до конца вегетации. Поскольку в фазах цветения и плодоношения некоторые флавонолгликозиды не были обнаружены, можно сделать вывод о наличии влияния времени сбора образцов на состав экстрактов $S$. media var. sericea, что необходимо учитывать в хемотаксономических исследованиях при сравнении видов. При этом состав основных компонентов постоянен во всех фазах, кроме цветения.

Следует отметить, что в образцах ни в одной из фаз не был выявлен изорамнетин, обнаруженный ранее в некоторых образцах, идентифицированных как $S$. media var. sericea [4].

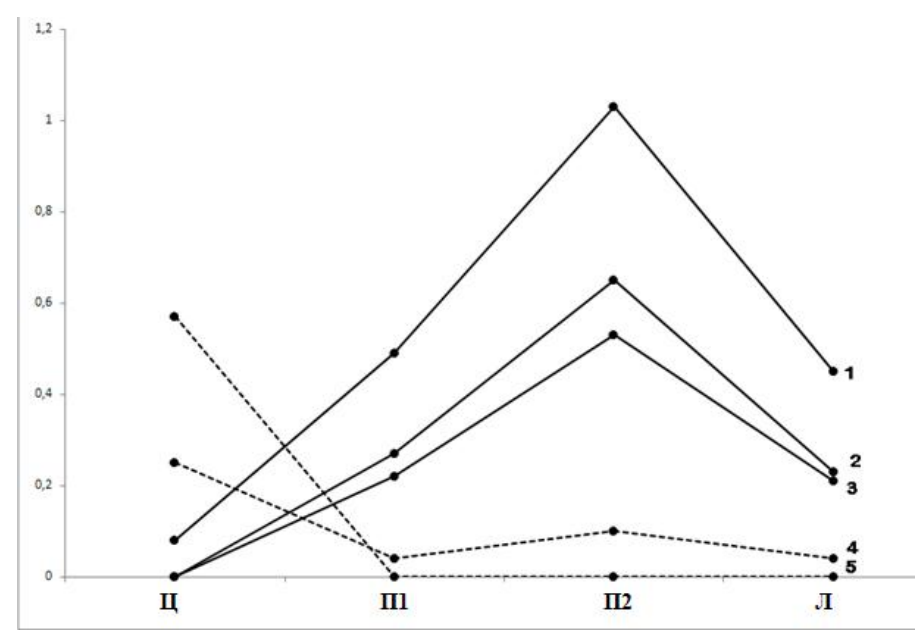

Рис. 5. Динамика флавонолгликозидов (\% от абсолютно сухой массы) в экстрактах S. media var. Sericea. Условные обозначения: 1 - гиперозид, 2 - неидентифицированный компонент 19, 3 - рутин, 4, 5 - неидентифицированные компоненты 17 и 13, Ц - цветение, П1 начало плодоношения, П2 - созревание плодов, Л - листопад

\section{Выводы}

Впервые изучен состав фенольных соединений $S$. media var. sericea в течение сезона вегетации. Основными компонентами комплекса фенольных соединений являются гликозиды кверцетина (гиперозид, неидентифицированный флавонолгликозид GM-19 и рутин).

В экстрактах в свободном виде обнаружены галловая, протокатеховая, хлорогеновая, кофейная кислоты. Кверцетин в свободном виде найден во всех фазах, кроме цветения.

Содержание большинства фенолкарбоновых кислот достигало максимума в фазе начала плодоношения, флавоноидов - в фазе созревания плодов. Некоторые флавонолгликозиды доминировали в сумме флавоноидов в фазе цветения. Наиболее полный состав флавонолгликозидов отмечен в начале плодоношения и при окончании вегетации, минимальный состав - в фазе цветения. Гиперозид и неидентифицированный флавонолгликозид GM-17 обнаружены во всех фазах вегетации.

Обнаружено постоянство состава агликонов, но различия в составе флавонолгликозидов в течение вегетации.

Выражаем глубокую признательность академику РАН П.Г. Горовому за ценные и подробные консультации. 


\section{Список литературы}

1. Полякова T.А. Внутривидовая изменчивость дальневосточных и сибирских видов рода Spiraea L.: автореф. дисс. ... канд. биол. наук. Новосибирск, 2004.

2. Карпова Е.А., Полякова Т.А. Фенольные соединения Spiraea L. из природных и интродукционных популяций Азиатской России // Фенольные соединения: фундаментальные и прикладные аспекты: мат. докладов VIII междунар. симпозиума. М., 2012. С. 304-309.

3. Bodalski T., Cisowski W. Flavonoids in the inflorescens of Spiraea media Schm. Dissertationes Pharmaceuticae et Pharmacologicae. PAN. 1969. Vol. 21, N5. Pp. 443-447.

Поступило в редакциию 25 октября 2013 г.

После переработки 7 февраля 2014 г.

Karpova E.A., Polyakova T.A. SEASONAL DYNAMICS OF THE COMPOSITION OF PHENOLIC COMPOUNDS OF THE LEAVES OF SPIRAEA MEDIA VAR. SERICEA (TURCZ.) REGEL

Central Siberian Botanical Garden of the Russian Academy of Sciences, Zolotodolinskaya, 101, Novosibirsk, 630090

(Russia),e-mail: karyevg@mail.ru

For the first time the dynamics of the composition of phenolic compounds of the leaves of plants of $S$. media var. sericea during the vegetative season was studied by HPLC. The main components of the phenolic compounds complex are quercetin glycosides. Flavonol glycosides contents peaked in ripening phase (3\%). The most complete flavonol glycosides composition was marked at the beginning of fruiting. In the extract in various phases of vegetation free forms of gallic, protocatechuic, chlorogenic, caffeic acids and quercetin were found. During the vegetative season constancy of the aglycone composition is remained together with certain differences in the flavonol glycosides composition.

Keywords: Spiraea, flavonoids, quercetin, seasonal dynamics.

\section{References}

1. Poljakova T.A. Vnutrividovaja izmenchivost' dal'nevostochnyh i sibirskih vidov roda Spiraea L. Avtoref. diss. ... kand. biol. nauk. [Intraspecific variation of Far Eastern and Siberian species of the genus Spiraea L. Synopsis diss. ... Candidate of biologikal Sciences]. Novosibirsk, 2004.

2. Karpova E.A., Poljakova T.A. Fenol'nye soedinenija: fundamental'nye i prikladnye aspekty. Materialy dokladov VIII mezhdunarodnogo simpoziuma. [Phenolic compounds: fundamental and applied aspects. Proceedings of the VIII International Symposium.]. Moscow, 2012, pp. 304-309.

3. Bodalski T., Cisowski W. Dissertationes Pharmaceuticae et Pharmacologicae. PAN, 1969, vol. 21, no. 5, pp. $443-447$. 
